Original article

\title{
The optimal utilization proportion of external beam radiotherapy in European countries: An ESTRO-HERO analysis is
}

\author{
Josep M. Borras ${ }^{\mathrm{a}, *}$, Yolande Lievens ${ }^{\mathrm{b}}$, Peter Dunscombe ${ }^{\mathrm{c}}$, Mary Coffey ${ }^{\mathrm{d}}$, Julian Malicki ${ }^{\mathrm{e}}$, Julieta Corral ${ }^{\mathrm{f}, \mathrm{g}}$, \\ Chiara Gasparotto ${ }^{\mathrm{h}}$, Noemie Defourny ${ }^{\mathrm{h}}$, Michael Barton ${ }^{\mathrm{i}}$, Rob Verhoeven ${ }^{\mathrm{j}}$, Liesbeth van Eycken ${ }^{\mathrm{k}}$, \\ Maja Primic-Zakelj ${ }^{1}$, Maciej Trojanowski ${ }^{\mathrm{m}}$, Primoz Strojan $^{\mathrm{n}}$, Cai Grau $^{\circ}$

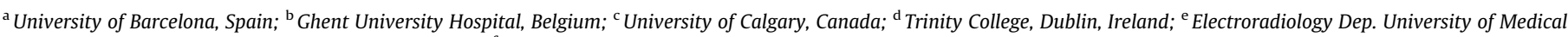

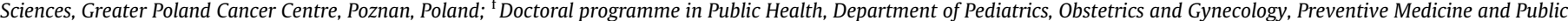

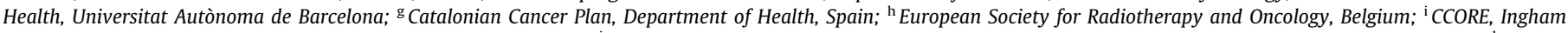

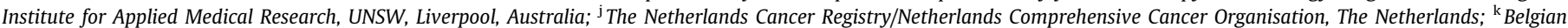

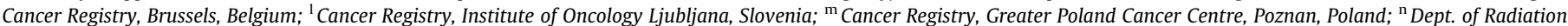 \\ Oncology, Institute of Oncology Ljubljana, Slovenia; ${ }^{\circ}$ Aarhus University Hospital, Denmark
}

\section{A R T I C L E I N F O}

\section{Article history:}

Received 16 March 2015

Accepted 29 April 2015

Available online $\mathrm{xxxx}$

\section{Keywords:}

Radiotherapy

Optimal utilization

European countries

Planning

\begin{abstract}
A B S T R A C T
Background and purpose: The absolute number of new cancer patients that will require at least one course of radiotherapy in each country of Europe was estimated.

Material and methods: The incidence and relative frequency of cancer types from the year 2012 European Cancer Observatory estimates were used in combination with the population-based stage at diagnosis from five cancer registries. These data were applied to the decision trees of the evidence-based indications to calculate the Optimal Utilization Proportion (OUP) by tumour site.

Results: In the minimum scenario, the OUP ranged from $47.0 \%$ in the Russian Federation to $53.2 \%$ in Belgium with no clear geographical pattern of the variability among countries. The impact of stage at diagnosis on the OUP by country was rather limited. Within the 24 countries where data on actual use of radiotherapy were available, a gap between optimal and actual use has been observed in most of the countries.

Conclusions: The actual utilization of radiotherapy is significantly lower than the optimal use predicted from the evidence based estimates in the literature. This discrepancy poses a major challenge for policy makers when planning the resources at the national level to improve the provision in European countries. (c) 2015 Elsevier Ireland Ltd. All rights reserved. Radiotherapy and Oncology xxx (2015) xxx-xxx
\end{abstract}

The estimated number of new cancer patients that require radiotherapy is a key parameter for planning the resources needed in a specific country in the framework of a cancer control programme. Most commonly, this calculation has been carried out using a specific proportion, typically the 'gold standard' of $50 \%$, of the incident cases that would require radiotherapy at least

Co-authors from HERO consortium: Arianit Kokobobo, University Hospital Center Mother Theresa, Tirana, Albania. Felix Sedlmayer, SALK and Paracelsus Medical

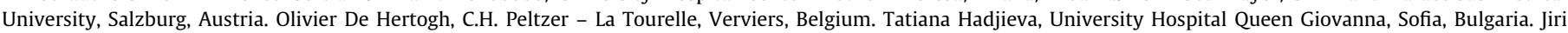

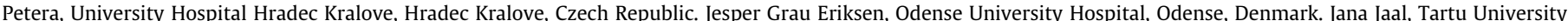

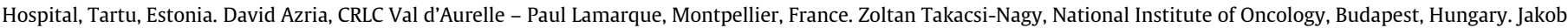

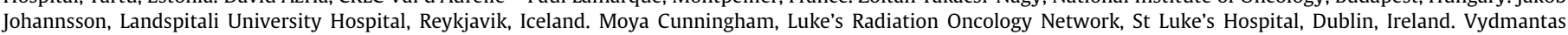

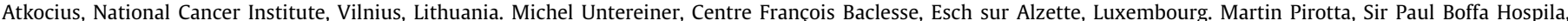

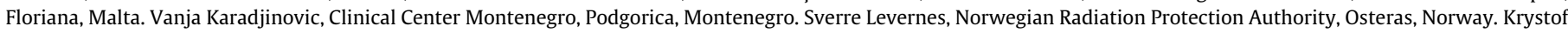

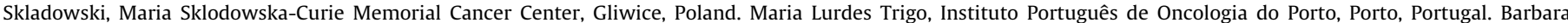

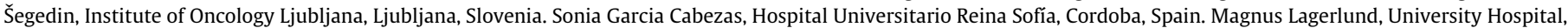

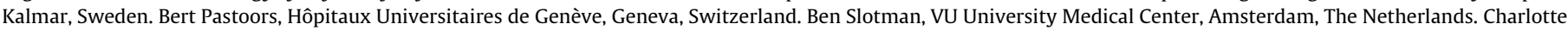

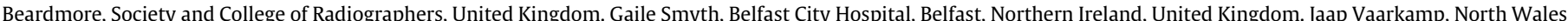

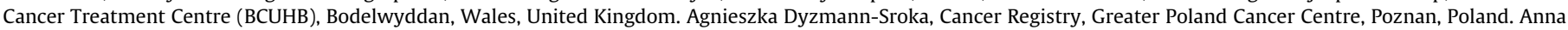

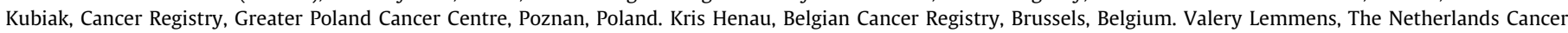
Registry.

* Corresponding author at: University of Barcelona - Hospital Duran i Reynals, Gran Via de l'Hospitalet, 199, 08908-Hospitalet del Llobregat, Barcelona, Spain.

E-mail address: jmborras@iconcologia.net (J.M. Borras). 
once during the course of his/her cancer. Although several more refined approaches have been developed to estimate this proportion developed by the Australian Collaboration for Cancer Outcomes Research and Evaluation (CCORE) can be considered the most optimal, as this approach involves a comprehensive and evidence-based analysis of all cancer sites [1] and has recently been updated [2]. In Australia this resulted in an optimal utilization proportion of $48.3 \%$, that is, $48.3 \%$ of all incident cancer cases would require a course of radiotherapy at least once in the course of the disease.

In addition to the indications for radiotherapy in each clinical pathway, key parameters to evaluate the OUP of radiotherapy are the relative frequencies of cancer types as well as the stage at diagnosis [3].

The differences across European countries in cancer incidence, both in absolute number and in relative frequency of each tumour are significant [4]. Thus, it is of crucial importance to take into account the existing differences in the relative frequency of various cancers across Europe when calculating the OUP for each individual country, and to evaluate its impact on the absolute number of new cancer patients that will require radiotherapy.

The objective of this study is a logical step forward within the ESTRO-HERO project, which is an ESTRO supported activity aimed at developing a knowledge base and a model for the health economic evaluation of radiation oncology in the European countries. Analyses of the resources available in the European countries were recently published [5-7]. This paper evaluates the evidence-based country-specific demand for radiotherapy across Europe in order to allow all stakeholders to be able to estimate the capital and human resources required to deliver an appropriate radiotherapy service.

\section{Material and methods}

In order to estimate the absolute number of new cancer patients that will require radiotherapy in each country, the number of new cancer cases estimated for the year 2012, was combined with the overall OUP of radiotherapy in different European countries.

The country specific absolute number of new cancer cases has been obtained for the countries included in the European Cancer Observatory (ECO) database, estimated for the year 2012, and based on projections from the population based cancer registries available [4]. For non-Hodgkins lymphoma and head and neck cancers, which required further subdivision by subtypes, data from population based cancer registries have been used.

The OUP has been calculated using the methodology developed by the Australian Collaboration for Cancer Outcomes Research and Evaluation (CCORE) group, using evidence based indications for radiotherapy for all tumour sites with more than $1 \%$ incidence $[1,2]$. Briefly summarized, the CCORE team reviewed all the relevant published evidence-based guidelines and the scientific literature, updated until 2012, regarding the indications for radiotherapy for different tumour sites and accounting for the entire range of relevant stages at diagnosis. Indication for radiotherapy was defined as meaning it was the treatment of choice because there was evidence that radiotherapy has a superior clinical outcome (either measured by survival, quality of life, lower toxicity profile or better local control) compared to the alternative modalities or no treatment, provided that the patient is fit enough to undergo treatment. Based on these data, the CCORE team developed a decision tree model to estimate, by tumour site and for all cancers overall, the proportion of patients in whom external beam radiotherapy would be recommended at some stage during the course of the disease. Pathway probabilities included the distribution of cancer incidence by tumour site, stage at diagnosis and relevant clinical characteristics of patients for each tumour (age and variations in performance status). The structure of the decision trees for each cancer site as well as the evidence supporting each clinical alternative and the corresponding probability of occurrence are available in the original report [8]. As neither retreatments nor brachytherapy were included in the CCORE decision trees, the focus of this analysis is exclusively on the optimal proportion of cancer patients receiving at least one course of external beam radiotherapy.

The relative frequency of each tumour is not only a necessary input for the calculation of the country-specific OUP, but also the main determinant of the inter-country OUP variation [3]. As shown in Table 1, which includes the relative percentages from the 12 most frequent cancers in Europe according to the ECO [4], the relative frequency varies significantly among countries. Stage at diagnosis, the other essential input parameter in the OUP calculation model, was not readily available in many cancer registries [9]. In a previous paper we have however shown that only a small part of the variability in overall OUP for radiotherapy was found among four European countries that have stage data available (i.e. Belgium, The Netherlands, Greater Poland region of Poland, and Slovenia), can be explained by the differences in stage distribution [3]. It can therefore be considered reasonable that the range of stage values from these four countries is representative of the other European countries. Hence, in order to assess the impact of stage distribution on the OUP in all ECO countries, we have applied the four different population based stage distributions, in addition to the Australian stage data, to each individual European country. The country specific range of OUP values are presented for all cancers combined.

All OUP calculations are carried out using the year 2012 as reference for the incidence and frequency data. The available data for stage at diagnosis from the population cancer registries are for the years 2009-11, depending on the cancer registry [3].

The number of radiotherapy courses obtained by combining the estimated number of new cancer cases for 2012 with the OUP by country, can be considered the 'optimal demand for radiotherapy' in each individual country. This number has been compared to the annual courses of radiotherapy delivered from the HERO database (provided by the National Societies, available years ranging from 2009 to 2011; with the corrections of the data included) [5] in order to assess the gap between optimal and actual delivered treatment courses.

Data on the number of actual courses delivered were provided in different ways: without including retreatments in several countries while other countries included retreatments in the total number of courses. To allow comparison between optimal and actual courses, retreatments should be excluded. Therefore, in the countries where retreatments were included, the courses were adjusted by a factor of 0.80 in order to compensate for the increment of $25 \%$ typically applied for retreatments [5]. This approach has been taken due to the lack of consistent data across European countries on the retreatments carried out; until now only local analyses have been published [10-12], mostly from outside Europe. Thus, the option here has been to focus on data for new cancer cases. All calculations were carried out using the Tree Age software.

\section{Results}

The variability of overall OUP by country, adjusted by stage at diagnosis from the five population-based cancer registries, is presented in Fig. 1. The variation by country is typically limited to between $1 \%$ and $2 \%$.

The numbers of new cancer cases estimated for the year 2012 in the 40 European countries included in this study are presented in Table 2, jointly with the calculated OUP by country. This OUP is 
Table 1

Estimated percentage of cancer cases by most frequent tumour site and country, 2012.

\begin{tabular}{|c|c|c|c|c|c|c|c|c|c|c|c|c|c|}
\hline Country & Bladder & Breast & $\begin{array}{l}\text { Corpus } \\
\text { uteri }\end{array}$ & Kidney & $\begin{array}{l}\text { Large } \\
\text { bowel }\end{array}$ & $\begin{array}{l}\text { Oral } \\
\text { cavity }\end{array}$ & Lung & $\begin{array}{l}\text { Melanoma of } \\
\text { skin }\end{array}$ & $\begin{array}{l}\text { Non-Hodgkin } \\
\text { lymph }\end{array}$ & Pancreas & Prostate & Stomach & $\begin{array}{l}\text { All } \\
\text { sites }\end{array}$ \\
\hline Albania & 5.9 & 14.3 & 3.1 & 3.2 & 4.8 & 3.0 & 15.4 & 0.5 & 0.4 & 2.8 & 4.7 & 11.7 & 100.0 \\
\hline Austria & 5.3 & 12.8 & 2.2 & 3.2 & 11.9 & 2.8 & 11.1 & 3.2 & 2.9 & 3.9 & 14.2 & 3.2 & 100.0 \\
\hline Belarus & 3.3 & 11.7 & 4.4 & 4.9 & 12.3 & 3.8 & 12.4 & 1.8 & 1.6 & 2.5 & 6.6 & 9.1 & 100.0 \\
\hline Belgium & 6.7 & 15.8 & 2.3 & 2.7 & 13.3 & 2.9 & 11.9 & 3.0 & 3.2 & 2.0 & 14.4 & 2.2 & 100.0 \\
\hline Bosnia & 4.7 & 11.6 & 3.3 & 2.9 & 11.2 & 2.9 & 17.4 & 1.1 & 1.2 & 2.6 & 7.0 & 5.3 & 100.0 \\
\hline Bulgaria & 5.2 & 12.3 & 4.0 & 2.7 & 15.4 & 2.7 & 12.3 & 1.4 & 1.7 & 3.9 & 5.7 & 5.2 & 100.0 \\
\hline Croatia & 4.6 & 11.5 & 2.6 & 3.6 & 14.0 & 3.0 & 13.4 & 2.9 & 2.4 & 3.0 & 8.8 & 4.2 & 100.0 \\
\hline Cyprus & 6.6 & 17.6 & 2.7 & 1.3 & 12.9 & 0.9 & 8.0 & 1.5 & 3.4 & 2.2 & 14.0 & 2.7 & 100.0 \\
\hline Czech Republic & 4.3 & 11.9 & 3.3 & 5.7 & 14.5 & 2.6 & 11.6 & 3.8 & 2.2 & 3.7 & 11.9 & 2.8 & 100.0 \\
\hline Denmark & 4.9 & 14.5 & 2.1 & 2.1 & 13.4 & 2.5 & 12.6 & 4.4 & 2.9 & 2.8 & 14.4 & 1.7 & 100.0 \\
\hline Estonia & 3.4 & 10.8 & 3.4 & 4.6 & 12.9 & 2.3 & 10.3 & 2.7 & 2.1 & 3.1 & 16.7 & 6.0 & 100.0 \\
\hline Finland & 3.8 & 15.7 & 3.0 & 3.1 & 10.2 & 2.0 & 8.8 & 4.2 & 4.2 & 4.0 & 18.9 & 2.3 & 100.0 \\
\hline France & 3.0 & 14.6 & 1.8 & 3.0 & 11.0 & 3.0 & 10.8 & 2.7 & 3.1 & 2.5 & 19.8 & 1.8 & 100.0 \\
\hline FYR Macedonia & 5.1 & 15.7 & 6.1 & 1.4 & 10.7 & 1.4 & 17.3 & 2.0 & 1.1 & 3.4 & 6.0 & 7.4 & 100.0 \\
\hline Germany & 5.8 & 14.5 & 2.3 & 3.8 & 12.9 & 3.2 & 10.3 & 3.4 & 3.0 & 3.3 & 13.8 & 3.2 & 100.0 \\
\hline Greece & 6.8 & 12.0 & 2.1 & 2.7 & 9.5 & 1.4 & 16.8 & 1.2 & 1.1 & 3.8 & 7.9 & 3.6 & 100.0 \\
\hline Hungary & 5.3 & 10.1 & 1.6 & 3.1 & 16.7 & 5.3 & 18.4 & 2.2 & 2.0 & 3.7 & 6.3 & 3.9 & 100.0 \\
\hline Iceland & 4.6 & 15.5 & 2.1 & 3.1 & 10.8 & 1.8 & 11.2 & 3.5 & 3.2 & 2.0 & 18.8 & 1.9 & 100.0 \\
\hline Ireland & 3.2 & 13.9 & 1.8 & 2.7 & 12.3 & 1.8 & 10.9 & 4.1 & 3.4 & 2.5 & 18.2 & 2.3 & 100.0 \\
\hline Italy & 5.2 & 14.3 & 2.4 & 3.2 & 13.6 & 1.6 & 10.5 & 2.8 & 3.5 & 3.0 & 12.6 & 3.7 & 100.0 \\
\hline Latvia & 4.1 & 11.1 & 3.8 & 4.3 & 11.1 & 2.1 & 11.4 & 2.2 & 1.8 & 3.6 & 14.3 & 6.2 & 100.0 \\
\hline Lithuania & 3.9 & 10.2 & 3.9 & 5.3 & 10.7 & 2.6 & 10.7 & 1.9 & 2.4 & 3.3 & 10.4 & 6.0 & 100.0 \\
\hline Luxembourg & 3.9 & 14.5 & 4.6 & 2.8 & 12.5 & 2.6 & 10.5 & 3.5 & 2.7 & 2.7 & 13.6 & 2.7 & 100.0 \\
\hline Malta & 6.9 & 16.5 & 3.4 & 3.0 & 14.1 & 2.7 & 9.5 & 1.9 & 2.6 & 3.9 & 10.6 & 3.6 & 100.0 \\
\hline Moldova & 3.5 & 11.2 & 3.5 & 2.3 & 15.3 & 4.4 & 12.5 & 1.2 & 2.1 & 4.4 & 4.4 & 6.2 & 100.0 \\
\hline Montenegro & 4.5 & 12.3 & 3.4 & 2.8 & 12.5 & 3.1 & 17.1 & 1.9 & 1.7 & 2.8 & 7.2 & 4.2 & 100.0 \\
\hline Norway & 4.9 & 10.2 & 2.7 & 2.8 & 13.9 & 1.9 & 10.1 & 5.3 & 3.2 & 2.6 & 20.5 & 1.7 & 100.0 \\
\hline Poland & 5.2 & 11.3 & 3.9 & 3.4 & 12.8 & 3.3 & 17.2 & 1.7 & 1.7 & 3.3 & 7.2 & 4.0 & 100.0 \\
\hline Portugal & 5.8 & 12.4 & 3.0 & 2.0 & 14.5 & 4.2 & 8.5 & 2.2 & 3.7 & 2.5 & 13.5 & 6.1 & 100.0 \\
\hline Romania & 4.9 & 11.4 & 2.0 & 2.5 & 13.0 & 4.7 & 14.8 & 1.4 & 2.0 & 3.9 & 5.8 & 5.2 & 100.0 \\
\hline Russia & 3.0 & 12.5 & 4.6 & 4.2 & 13.1 & 3.2 & 12.2 & 1.9 & 1.7 & 3.2 & 5.9 & 8.4 & 100.0 \\
\hline Serbia & 4.4 & 12.8 & 3.4 & 2.7 & 13.1 & 3.1 & 17.2 & 2.4 & 2.1 & 3.0 & 7.4 & 3.5 & 100.0 \\
\hline Slovakia & 3.9 & 11.0 & 3.9 & 4.4 & 16.5 & 4.1 & 10.5 & 3.4 & 2.4 & 3.7 & 8.0 & 3.7 & 100.0 \\
\hline Slovenia & 4.0 & 11.0 & 2.7 & 3.5 & 14.1 & 2.8 & 11.9 & 4.7 & 2.6 & 3.3 & 13.7 & 4.1 & 100.0 \\
\hline Spain & 6.4 & 11.7 & 2.4 & 3.0 & 15.0 & 2.8 & 12.4 & 2.3 & 2.8 & 3.0 & 12.9 & 3.6 & 100.0 \\
\hline Sweden & 4.7 & 13.1 & 2.8 & 2.2 & 12.6 & 1.9 & 7.7 & 5.8 & 3.2 & 1.9 & 23.0 & 1.6 & 100.0 \\
\hline Switzerland & 5.0 & 13.7 & 2.4 & 2.3 & 11.6 & 2.8 & 10.1 & 5.9 & 3.6 & 2.8 & 18.7 & 1.6 & 100.0 \\
\hline The Netherlands & 3.2 & 14.9 & 2.2 & 2.9 & 14.9 & 2.2 & 12.8 & 5.1 & 3.5 & 2.3 & 14.2 & 2.1 & 100.0 \\
\hline Ukraine & 3.5 & 11.7 & 4.9 & 3.7 & 13.5 & 4.1 & 12.2 & 2.0 & 1.5 & 3.4 & 4.7 & 8.1 & 100.0 \\
\hline UK & 2.7 & 16.0 & 2.6 & 3.0 & 12.4 & 2.3 & 12.3 & 4.4 & 3.6 & 2.7 & 13.9 & 2.0 & 100.0 \\
\hline Europe & 4.4 & 13.5 & 2.9 & 3.3 & 13.0 & 2.9 & 11.9 & 2.9 & 2.7 & 3.0 & 12.1 & 4.1 & 100.0 \\
\hline
\end{tabular}

Source: European Cancer Observatory (www. eco.iarc.fr/).

calculated by applying each stage data set, thus obtaining 5 different OUPs by country, and the highest and the lowest OUP are presented in the table.

Globally speaking, out of 3.41 million new cancer cases diagnosed in European countries in 2012, 1.74 million patients (unweighted average percentage of OUP between the highest and lowest stages of $51.0 \%$ ) should have received at least one radiotherapy course following the evidence-based approach used in the present analysis. Using the stage distribution that provides the lower estimate of OUP, the variation in OUP by country ranged from the lowest in the Russian Federation with $47.0 \%$ to the highest in Belgium with $53.2 \%$; or an absolute $6.2 \%$ difference is observed. No clear geographical pattern can be observed with respect to the OUP distribution.

The available numbers of radiotherapy courses by country from the HERO database are also presented in Table 2. The gap between the actual number and the optimal utilization obtained from the evidence-based model, expressed as a percentage, is calculated. This gap is presented in Fig. 2 as a percentage of the total number of patients that would have required, at least once, a radiotherapy course according to the OUP by country. Globally speaking, 4 countries treated at least $80 \%$ of the optimal indications for radiotherapy and 11 countries not even reached $70 \%$ of the patients optimally indicated. Of interest is that just one country reports a utilization of radiotherapy in excess to the figures proposed by the OUP range.

\section{Discussion}

The unique contribution of this study is the estimate of the optimal utilization proportion (OUP) of radiotherapy for 40 European countries. For each country, specific relative frequencies of the most common cancers were taken into account as well as realistic estimates of the ranges of stages at diagnosis from population based cancer registries. Previous attempts to calculate the number of new cancer cases that would require radiotherapy have only considered a unique proportion, usually $50 \%$ of new cancer cases plus $25 \%$ retreatments, $62.5 \%$ in total $[13,14]$, all following the recommendations previously presented in the QUARTS project [15] that was based on the initial CCORE study.

Although the information on the distribution of cancer stages at diagnosis was not available for the majority of countries, which is a shortcoming, stage at diagnosis data from five population based cancer registries allowed us to take into account this second factor in the estimation of the OUP. The difficulties in collecting data on stage in population cancer registries are well known [9] and the number of registries with this information available is rather 


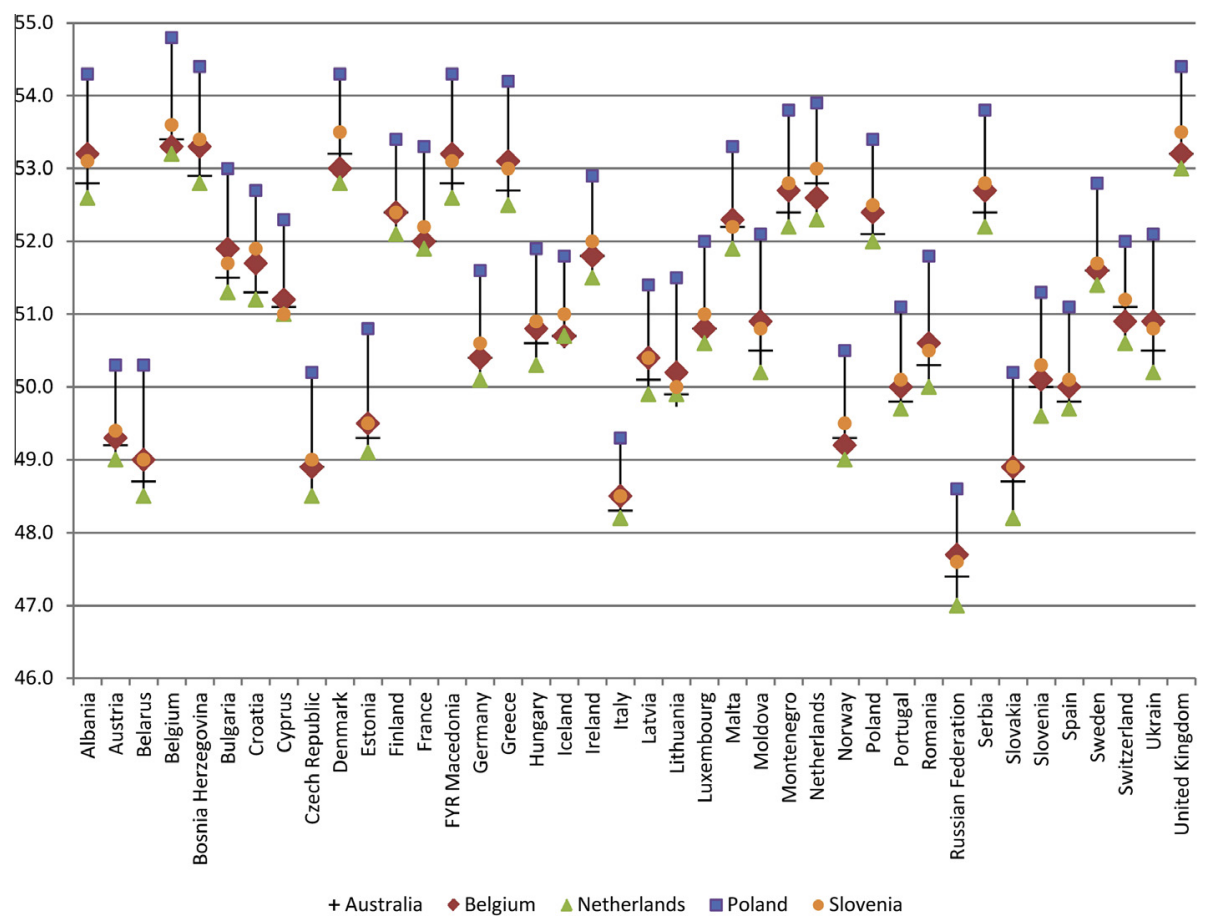

Fig. 1. Range of values for overall optimal utilization proportion by country (in percentages of total cancer incidence).

limited. However, the four national sets of stage data together with those from Australia allowed us to create a range of values that could be considered as encompassing the majority of health services across Europe. In addition, we have assessed, in a previous paper, the differential impact of relative frequencies of tumours and stage distributions in five countries. The fact is that the relative frequency of tumours showed a higher impact on the OUP than stage distribution due to its more general influence on the decision trees [3]. The stage is very relevant to OUP in some specific tumour sites, such as rectal or cervical cancer, but not in others which significantly influence the demand for radiotherapy, such as breast or prostate cancer. Thus, it could be concluded that the lack of stage data for most countries has only a limited impact on the estimated national OUPs and the size of the impact can be judged from the rather small influence of the different stage distributions from the five countries for which data were available.

The approach applied here has shown that the variation in frequency distribution of individual cancer sites significantly affects the OUP calculation and hence the estimation of demand for radiotherapy with the concomitant resources - equipment and personnel - needed to cope with these new cancer cases. For instance, and using Belgium as an example, the OUP is 53.3\%; using its own stage data [3]; a difference of $5.0 \%$ from the Australian estimate of $48.3 \%$ [2]. This difference represents 3267 additional patients with an indication for radiotherapy (excluding retreatments), implying the need for 7.8 linear accelerators, based on the average throughput of 420 courses of radiotherapy per MV unit in the European countries or 8.5 based on the Belgian average number of patients treated on a linear accelerator [5]. This illustrates how the differences calculated, even if they may seem small, could have a substantial impact on the calculation of the resources needed. The same example for Spain would result in an extra 7.2 linear accelerators. It can be concluded that the country-specific adjustment for the epidemiological situation by country may result in a more reliable estimate, which would provide a better basis to estimate the need for equipment and staff for radiotherapy, and consequently, more accurate planning at the national level.
The discrepancy between evidence based recommendations and the reality of the provision of health services poses a challenge for policy makers, although the range of discrepancies varies significantly among countries. The relevant question in this framework is why the actual utilization of radiotherapy is lower than it should be according to the evidence. In fact, several recent studies carried out in countries with high survival rates, a good indicator of quality of cancer care [16], such as the Netherlands or Norway, have shown that the proportion of patients receiving radiotherapy treatment is lower than expected. For instance, between 1997 and 2008, external beam radiotherapy was used in only $25 \%$ of the patients with a diagnosis of prostate cancer in the Netherlands [17], markedly lower than the OUP of about $60 \%$, even taking into account that the utilization data from the Netherlands were restricted to the first 6 months after diagnosis. The situation was similar in non-small cell lung cancer [18] with $40 \%$ actual utilization, far below the calculated $80 \%$; but it was not the case in rectal cancer, which showed a $71 \%$ of utilization [19] slightly higher than expected from CCORE model. Furthermore, in Norway [10], a lower utilization of radiotherapy during the first 5 years after diagnosis was found for all tumours in comparison with the evidence based recommendations. They also analyzed specifically the most frequent indications (breast, prostate, lung, colorectal, and head and neck cancers) and they observed a lower utilization than predicted, with the exception of breast cancer.

The discrepancy between evidence based OUPs and actual use of radiotherapy could be explained by different factors that are relevant when planning investments in radiotherapy resources.

- First of all, reduced use of radiotherapy has been associated with limitations due to geographical access [20], with specific impact on palliative radiotherapy [21].

- Second, the presence of comorbidity, particularly when combined with older age, is usually associated with the under-utilization of radiotherapy [22,23]. It should be recognized, however, that in specific indications such as muscle 
Table 2

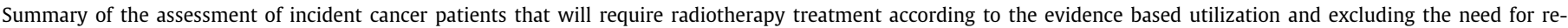
treatment.

\begin{tabular}{|c|c|c|c|c|c|c|c|c|}
\hline \multirow[t]{2}{*}{ Country } & \multirow[t]{2}{*}{ Total cancers $(n)^{\mathrm{a}}$} & \multicolumn{2}{|c|}{$\operatorname{OUP}(\%)^{\mathrm{b}}$} & \multicolumn{2}{|c|}{ Optimal RT courses $(n)$} & \multirow[t]{2}{*}{ Actual RT courses $(n)^{\mathrm{c}}$} & \multicolumn{2}{|c|}{$\begin{array}{l}\text { Actual/optimal RT courses } \\
\text { (\%) }\end{array}$} \\
\hline & & Min. & Max. & OUP min. & OUP max. & & OUP min. & OUP max. \\
\hline Albania & 7143 & 52.6 & 54.3 & 3758 & 3879 & 2195 & 58.4 & 56.6 \\
\hline Austria & 41,117 & 49.0 & 50.3 & 20,155 & 20,698 & 17,185 & 85.3 & 83.0 \\
\hline Belarus & 32,422 & 48.5 & 50.3 & 15,738 & 16,293 & NA & & \\
\hline Belgium & 65,345 & 53.2 & $54.8^{\mathrm{d}}$ & 34,792 & 35,799 & 27,738 & 79.7 & 77.5 \\
\hline Bosnia Herzegovina & 9911 & 52.8 & 54.4 & 5236 & 5395 & NA & & \\
\hline Bulgaria & 32,053 & 51.3 & 53.0 & 16,434 & 16,977 & 11,035 & 67.1 & 65.0 \\
\hline Croatia & 22,890 & 51.2 & 52.7 & 11,717 & 12,055 & NA & & \\
\hline Cyprus & 3438 & 51.0 & 52.3 & 1753 & 1799 & NA & & \\
\hline Czech Republic & 57,627 & 48.5 & 50.2 & 27,943 & 28,945 & 26,104 & 93.4 & 90.2 \\
\hline Denmark & 36,119 & 52.8 & 54.3 & 19,064 & 19,600 & 14,144 & 74.2 & 72.2 \\
\hline Estonia & 6117 & 49.1 & 50.8 & 3004 & 3104 & 1698 & 56.5 & 54.7 \\
\hline Finland & 28,428 & 52.1 & 53.4 & 14,810 & 15,189 & NA & & \\
\hline France & 371,676 & 51.9 & 53.3 & 192,769 & 198,107 & 149,738 & 77.7 & 75.6 \\
\hline FYR Macedonia & 7330 & 52.6 & 54.3 & 3856 & 3981 & NA & & \\
\hline Germany & 493,780 & 50.1 & 51.6 & 247,419 & 254,735 & NA & & \\
\hline Greece & 40,971 & 52.5 & 54.2 & 21,523 & 22,213 & NA & & \\
\hline Hungary & 50,475 & 50.3 & 51.9 & 25,412 & 26,209 & 15,961 & 62.8 & 60.9 \\
\hline Iceland & 1449 & 50.7 & 51.8 & 734 & 750 & 476 & 64.8 & 63.5 \\
\hline Ireland & 20,808 & 51.5 & 52.9 & 10,714 & 11,017 & 6,698 & 62.5 & 60.8 \\
\hline Italy & 354,456 & 48.2 & 49.3 & 170,821 & 174,764 & NA & & \\
\hline Latvia & 10,347 & 49.9 & 51.4 & 5166 & 5315 & NA & & \\
\hline Lithuania & 14,520 & 49.9 & 51.5 & 7242 & 7483 & 5,014 & 69.2 & 67.0 \\
\hline Luxembourg & 2476 & 50.6 & 52.0 & 1252 & 1289 & 944 & 75.4 & 73.3 \\
\hline Malta & 1,902 & 51.9 & 53.3 & 988 & 1014 & 535 & 54.2 & 52.8 \\
\hline Moldova & 9894 & 50.2 & 52.1 & 4969 & 5151 & NA & & \\
\hline Montenegro & 2115 & 52.2 & 53.8 & 1105 & 1139 & 1200 & 108.6 & 105.4 \\
\hline Netherlands & 93,448 & 52.3 & $53.9^{\mathrm{e}}$ & 48,886 & 50,324 & 44,546 & 91.1 & 88.5 \\
\hline Norway & 28,214 & 49.0 & 50.5 & 13,818 & 14,248 & 10,786 & 78.1 & 75.7 \\
\hline Poland & 152,216 & 52.0 & $53.4^{\mathrm{f}}$ & 79,139 & 81,294 & 58,800 & 74.3 & 72.3 \\
\hline Portugal & 49,174 & 49.7 & 51.1 & 24,438 & 25,151 & 14,366 & 58.8 & 57.1 \\
\hline Romania & 78,760 & 50.0 & 51.8 & 39,383 & 40,805 & NA & & \\
\hline Russian Federation & 458,382 & 47.0 & 48.6 & 215,507 & 222,922 & NA & & \\
\hline Serbia & 42,221 & 52.2 & 53.8 & 22,050 & 22,733 & NA & & \\
\hline Slovakia & 24,045 & 48.2 & 50.2 & 11,599 & 12,071 & NA & & \\
\hline Slovenia & 11,457 & 49.6 & $51.3^{g}$ & 5680 & 5874 & 3603 & 63.4 & 61.3 \\
\hline Spain & 215,534 & 49.7 & 51.1 & 107,018 & 110,159 & 78,820 & 73.7 & 71.6 \\
\hline Sweden & 50,481 & 51.4 & 52.8 & 25,928 & 26,662 & 18,142 & 70.0 & 68.0 \\
\hline Switzerland & 42,046 & 50.6 & 52.0 & 21,294 & 21,865 & 15,200 & 71.4 & 69.5 \\
\hline Ukraine & 140,999 & 50.2 & 52.1 & 70,811 & 73,403 & NA & & \\
\hline United Kingdom & $297,227^{\mathrm{h}}$ & 53.0 & 54.4 & 157,414 & 161,760 & $105,531^{\mathrm{i}}$ & 67.0 & 65.2 \\
\hline Global & $3,409,013$ & 50.2 & 51.7 & $1,711,337$ & $1,762,171$ & & & \\
\hline
\end{tabular}

NA: Not-available.

a All cancers excl. non-melanoma skin cancer. Globocan 2012.

b OUP: optimal utilization proportion.

c Excluding re-treatment.

d OUP calculated from population based stage at diagnosis from country cancer registry: $53.3 \%$.

e OUP calculated from population based stage at diagnosis from country cancer registry: $52.3 \%$.

${ }^{\mathrm{f}}$ OUP calculated from population based stage at diagnosis from country cancer registry: $53.4 \%$.

g OUP calculated from population based stage at diagnosis from country cancer registry: $50.3 \%$.

h Scotland not included.

i Scotland not available.

invasive bladder cancer, where surgery is indicated, radiotherapy could be the preferred option with increased utilization in the elderly with comorbidity [24].

- Third, comparable effects were seen from patient-related factors such as the lower socio-economic level [25].

- A fourth relevant aspect is the preference of the physician for one therapeutic option over alternatives. In a paper published some years ago urologists and radiation oncologists were presented with the same clinical scenarios in order to assess their beliefs and therapeutic recommendations for prostate cancer. The result was not surprising that the specialists recommend the therapy that they deliver for the same clinical cases $(72 \%$ of the radiation oncologists believed that external beam radiotherapy and surgery were equivalents while 93\% of urologists believed that radical prostatectomy was the preferred option).
Beyond the specific clinical example, the paper clearly showed the bias favouring known clinical pathways that in some cases could exclude radiotherapy, although there is an evidence base for the indication [26]. Thus, lack of awareness, personal belief or knowledge could be another reason for the lower use of a particular treatment modality than expected considering evidence based data.

- A fifth factor is the shortage of resources, which resulted in waiting lists, delays in initiation of radiotherapy and reduced effectiveness of the treatment [20]. Such situations are unavoidably destinated to translate into lower utilization of radiotherapy. Shortage of resources is, at least in part, related to the specific financing structure within a country.

- This brings us to the last well-known factor that drives practice: the prevailing reimbursement in the country and the ensuing 


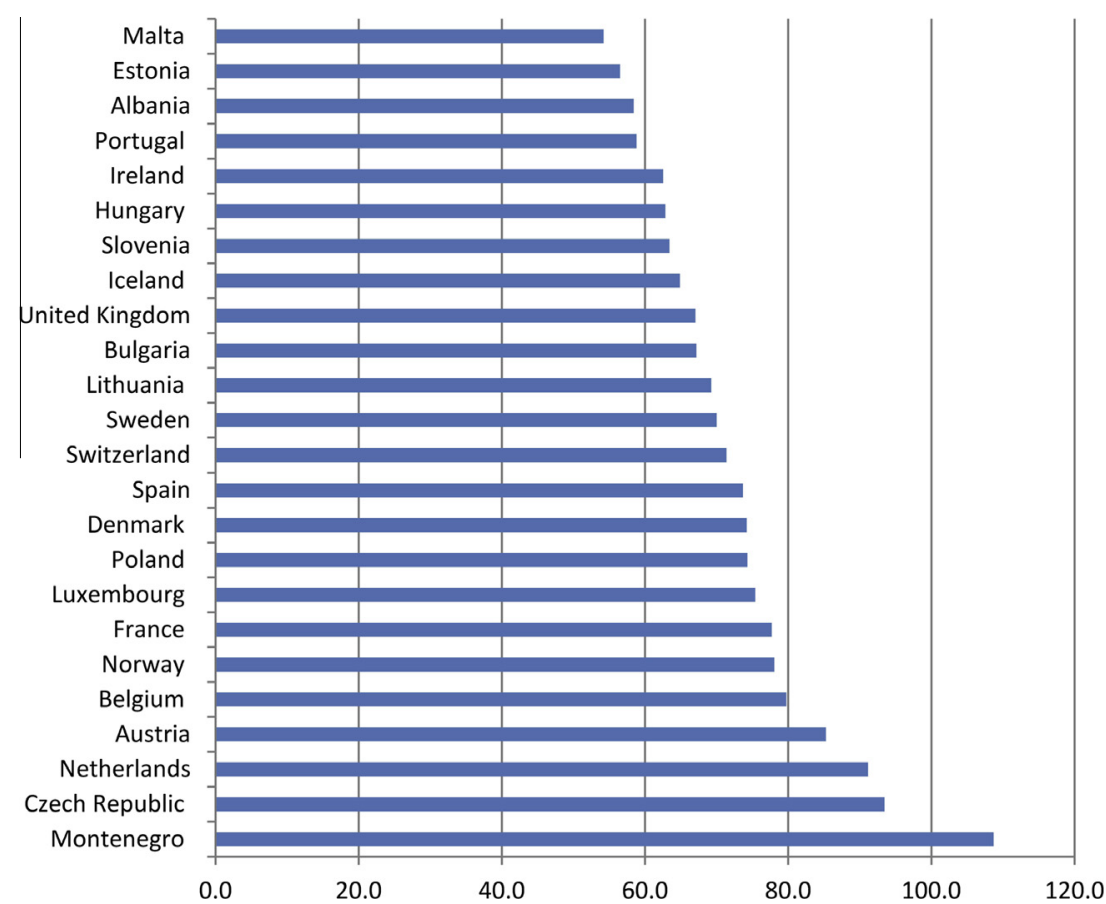

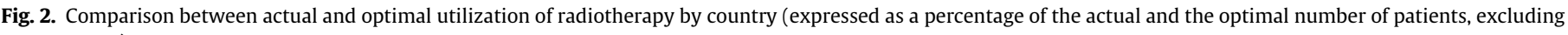
retreatments).

financial (dis)incentives. In the case of radiotherapy, reimbursement mechanisms may play a role in the choice of treatment complexity or fractionation, as has been observed when the higher reimbursement of IMRT for prostate cancer fuelled its use in the US, or when fee-for-service reimbursement endorsed the use of more protracted schedules for the palliation of bone metastases, thus limiting the evidence-based use of single fractions $[27,28]$. Also, the fact that radiation oncology depends on the referral pattern of other specialists, adds complexity to this issue. But it is not impossible that, at the national level, the intricate interplay of the financing systems in oncology may result in radiotherapy being less attractive than competing oncologic treatment strategies.

Hence, translating evidence-based indications for radiotherapy into clinical practice requires taking into account all the above factors, with an emphasis on organizational factors related to accessibility and availability of capital resources and trained staff as well as the promotion of appropriate indications in a multidisciplinary framework of high quality cancer care, all endorsed by the appropriate financing mechanisms.

In order to fully assess these results, some limitations should be taken into account. The possible limitation of the OUP having been estimated with stage distributions from only five population based cancer registry data has been discussed above. Analyses, such as the one presented, are inherently limited by the timely and complete collection of data: for the estimates of the gap between actual and optimal utilization, the latter refers to the year 2012 while the data on actual utilization are not $[5,6]$. Variations in radiotherapy activity are, however, extremely dependent on facilities being opened or renovated and additional personnel being trained, both typically spreading over long time periods. Hence we feel that the impact of the differential timing of actual and calculated utilization on the estimated gap should not be too important, with possible local exceptions that could be included in the range of values estimated for each country. The last serious limitation is that the actual utilization is only available in about half of the countries. Thus, the discussion about the gap is limited to those countries that have data on this key aspect of the planning of radiotherapy facilities and associated personnel. This point deserves careful consideration by the health care decision makers as the lack of essential data may seriously hamper rational planning of radiotherapy services.

In conclusion, the OUP for radiotherapy in the European countries has been estimated from an evidence-based assessment of the indications for radiotherapy, taking into account the differences in the relative frequency of cancer sites by country as well as a range of population based data on stage at diagnosis from five countries. A large discrepancy was observed between the actual utilization and the optimal utilization of radiotherapy in European countries, with less than $17 \%$ of countries treating at least $80 \%$ of the optimal indications for radiotherapy and about $46 \%$ of the European countries not even reaching $70 \%$ of the patients optimally indicated. These data should be taken into account when planning the resources at the national level and should support the development of guidelines for required resources and for cancer control plans.

\section{Conflicts of interest}

The authors have no conflict of interest.

\section{Funding sources}

This project was supported by the European Society for Radiotherapy and Oncology.

\section{References}

[1] Delaney G, Jacob S, Featherstone C, Barton M. The role of radiotherapy in cancer treatment: estimating optimal utilization from a review of evidencebased clinical guidelines. Cancer 2005;104:1129-37 (Erratum in: Cancer. 2006;107(3):660).

[2] Barton MB, Jacob S, Shafiq J, et al. Estimating the demand for radiotherapy from the evidence: a review of changes from 2003 to 2012. Radiother Oncol 2014;112:140-4. 
[3] Borràs JM, Barton MB, Grau C, et al. Impact of cancer incidence and stage on the optimal utilization of radiotherapy: methodology of a population based analysis by ESTRO-HERO project (2015, in press).

[4] Ferlay J, Sterialova-Foucher E, Lortet-Tieulent J, et al. Cancer incidence and mortality patterns in Europe: estimates for 40 countries in 2012. Eur J Cancer 2013;49:1374-403.

[5] Grau C, Defourney N, Malicki J, et al. Radiotherapy equipment and departments in the European countries: final results from the ESTRO-HERO survey. Radiother Oncol 2014;112:155-64.

[6] Lievens Y, Defourny N, Coffey M, et al. Radiotherapy staffing in the European countries: final results from the ESTRO-HERO survey. Radiother Oncol 2014;112:178-86.

[7] Dunscombe P, Grau C, Defourny N, et al. Guidelines for equipment and staffing of radiotherapy facilities in the European countries: final results of the ESTROHERO survey. Radiother Oncol 2014;112:165-77.

[8] Ingham Institute for Applied Medical Research (IIAMR) - Collaboration for Cancer Outcomes Research and Evaluation (CCORE). Review of optimal radiotherapy utilisation rates. CCORE report; 2013. Available from: tinyurl.com/pwkua34 [accessed 26-11-2014].

[9] Siesling S, Kwast A, Gavin A, Baili P, Otter R. EUROCHIP-3 Workpackage 5. Availability of stage at diagnosis, cancer treatment delay and compliance with cancer guidelines as cancer registry indicators for cancer care in Europe: results of EUROCHIP-3 survey. Int J Cancer 2013;132:2910-7.

[10] Asli L, Kvaloy S, Jetne V, et al. Utilization of radiation therapy in Norway after the implementation of the National cancer plan - A National, populationbased study. Int J Radiation Oncol Biol Phys 2014;90:707-14.

[11] Khor R, Bressel M, Tai KH, et al. Patterns of retreatment with radiotherapy in a large academic centre. J Med Imaging Radiother Oncol 2013;57:610-6.

[12] Barton MB, Allen S, Delaney GP, et al. Patterns of retreatment by radiotherapy. Clin Oncol 2014;26:611-8.

[13] Rosenblatt E, Izewska J, Anacak Y, et al. Radiotherapy capacity in European countries: an analysis of the Directory of Radiotherapy Centres (DIRAC) database. Lancet Oncol 2013;14:e79-86.

[14] Datta NR, Samei M, Bodis S. Radiotherapy infrastructure and human resources in Europe: present status and its implications for 2020. Eur J Cance 2014;50:2735-43.

[15] Bentzen S, Heeren G, Cottier B, et al. Towards evidence based guidelines for radiotherapy infrastructure and staffing needs in Europe: the ESTROQUARTS project. Radiother Oncol 2005;75:355-65.
[16] De Angelis R, Sant M, Coleman MP, et al. Cancer survival in Europe 1999-2007 by country and age: results of EUROCARE-5-a population-based study. Lancet Oncol 2014;15:23-34.

[17] Poortmans PMP, Aarts MJ, Jobsen JJ, et al. A population based study on the utilisation of primary radiotherapy for prostate cancer in 4 regions in the Netherlands, 1997-2008. Radiother Oncol 2011;99:207-13.

[18] Koning CCE, Aarts MJ, Struikmans H, et al. Mapping the use of radiotherapy for patients with non-small cell lung cancer in the Netherlands between 19972008. Clin Oncol 2012;24:e46-53.

[19] Jobsen JJ, Aarts MJ, Siesling S, et al. Use of primary radiotherapy for rectal cancer in the Netherlands between 1997 and 2008: a population based study. Clin Oncol 2012;24:e1-8.

[20] Mckillop WJ. Killing time: the consequences of delay in radiotherapy. Radiother Oncol 2007;84:1-4.

[21] Popovic M, den Hartog M, Zhang L, et al. Review of international patterns of practice for the treatment of painful bone metastases with palliative radiotherapy from 1993 to 2013. Radiother Oncol 2014;111:11-7.

[22] Vulto A, Louwman M, Rodrigus P, Coebergh JW. Referral rates and trends in radiotherapy as part of primary treatment of cancer in South Netherlands, 1998-2002. Radiolther Oncol 2006;78:131-7.

[23] Chawla N, Butler EN, Lund J, Warren JL, Harlan LC, Yabroff KR. Patterns of colorectal cancer care in Europe, Australia and New Zealand. JNCI Monograph 2013:46:36-60.

[24] Goossens-Laan C, Leliveld AM, Verhoeven R, et al. Effects of age and comorbidity on treatment and survival of patients with muscle invasive bladder cancer. Int J Cancer 2014;135:905-12.

[25] Aarts MJ, Lemmens VE, Louwman MW, Kunst AE, Coebergh JW. Socioeconomic status and changing inequalities in colorectal cancer? A review of the association with risk, treatment and outcome. Eur J Cancer 2010;46: 2681-95.

[26] Fowler F, Collins M, Albertsen P, et al. Comparison of recommendations by urologists and radiation oncologists for treatment of clinically localized prostate cancer. JAMA 2000;283:3217-22.

[27] Jacobs BL, Zhang Y, Skolarus TA, Hollenbeck BK. Growth of high-cost intensitymodulated radiotherapy for prostate cancer raises concerns about overuse. Health Affairs (Project Hope) 2012;31:750-9.

[28] Lievens Y, Van den Bogaert W, Rijnders A, Kutcher G, Kesteloot K. Palliative radiotherapy practice within Western European countries: impact of the radiotherapy financing system? Radiother Oncol 2000;56:289-95. 